LBNL - 59363

\title{
Meta-Analyses of the Associations of Respiratory Health Effects with Dampness and Mold in Homes
}

\author{
William J Fisk, Quanhong Lei-Gomez, Mark J. Mendell \\ Environmental Energy Technologies Division \\ Indoor Environment Department \\ Lawrence Berkeley National Laboratory \\ Berkeley, CA 94720
}

January 2006

This work was supported by the Indoor Environments Division, Office of Radiation and Indoor Air, Office of Air and Radiation of the U.S. Environmental Protection Agency through interagency agreement DW-89-92175001-0 with the U.S. Department of Energy Contract No. DE-AC02-05CH11231. 
LBNL -59361

\title{
Meta-Analyses of the Associations of Respiratory Health Effects with Dampness and Mold in Homes
}

\author{
William J Fisk, Quanhong Lei-Gomez, Mark J. Mendell \\ Indoor Environment Department, Lawrence Berkeley National Laboratory \\ Berkeley, CA 94720
}

\begin{abstract}
The Institute of Medicine (IOM) of the National Academy of Sciences recently completed a critical review of the scientific literature pertaining to the association of indoor dampness and mold contamination with adverse health effects. In this paper, we report the results of quantitative meta-analysis of the studies reviewed in the IOM report. We developed point estimates and confidence intervals (CIs) to summarize the association of several respiratory and asthma-related health outcomes with the presence of dampness and mold in homes. The odds ratios and confidence intervals from the original studies were transformed to the log scale and random effect models were applied to the log odds ratios and their variance. Models were constructed both accounting for the correlation between multiple results within the studies analyzed and ignoring such potential correlation. Central estimates of ORs for the health outcomes ranged from 1.32 to 2.10 , with most central estimates between 1.3 and 1.8. Confidence intervals (95\%) excluded unity except in two of 28 instances, and in most cases the lower bound of the $\mathrm{CI}$ exceeded 1.2. In general, the two meta-analysis methods produced similar estimates for ORs and CIs. Based on the results of the meta-analyses, building dampness and mold are associated with approximately $30 \%$ to $80 \%$ increases in a variety of respiratory and asthma-related health outcomes. The results of these meta-analyses reinforce the IOM's recommendation that actions be taken to prevent and reduce building dampness problems.
\end{abstract}

\section{INTRODUCTION}

The association of adverse health effects with dampness and mold in buildings has been the subject of much research. Most studies on this topic have found an increased risk of one or more adverse health effects in buildings with signs of dampness or visible mold. The Institute of Medicine (IOM) of the National Academy of Sciences recently completed a critical review (IOM 2004) of this scientific literature. The IOM concluded that excessive indoor dampness is a public health problem, noted that dampness problems are common, and recommended corrective measures. While the IOM report summarized the main features and results of the reviewed studies, which included a broad range of health outcomes, it provided no quantitative summaries of these studies. 
In this paper, we report the results of quantitative meta-analyses of the studies reviewed in the IOM report. A meta-analysis uses statistical methods to combine data from different but comparable research studies, in order to provide a quantitative summary on the size and variability of an association. Studies are generally selected for relevance, quality, and similarity. The contribution of larger, more precise studies to the summary estimate is generally more heavily weighted. Results of meta-analyses presented here are central point estimates and confidence intervals (CIs) of odds ratios (ORs) that summarize the magnitude of increased risk of several health outcomes in buildings with dampness and mold. The central estimates and CIs of ORs, if assumed to reflect causality, can be used to communicate the importance of dampness and mold as health risks, to estimate the economic significance of dampness- and mold-related health effects to society, and to estimate the magnitude of health and economic benefits from programs that reduce dampness and mold.

\section{METHODS}

We began with the full list of studies included in Tables 5-1, 5-2, 5-3, 5-6, 5-7, 5-8 of the recent IOM review (IOM 2004). Details on the studies included in the meta-analyses are provided in Appendix 1.

Ideally, meta-analyses would combine estimates only from studies with the same precisely defined health outcome, risk factor, and population/subjects. Because the original studies included many differently defined respiratory health outcomes, risk factors, and populations, this was not possible, and we analyzed groups of studies that were as similar as practicable with respect to these. Table 1 shows the health outcome categories and specific outcomes from the studies included in each category.

\section{$\underline{\text { Subject types }}$}

We grouped studies by subject type. The reviewed studies included diverse populations: adults, male adults, female adults, children (age $<18$ ), and children (infants). We performed, where possible, separate analyses for: adults (including studies of mixed or single gender), children (including studies of age $<18$ or infants), and all ages combined. However, for ever-diagnosed with asthma and asthma development, too few studies were available to support separate metaanalyses for children and adults.

\section{$\underline{\text { Risk factors }}$}

In general, the risk factors in the reviewed studies included were visible signs of dampness, visible mold, dampness or mold, dampness and mold, and measured concentrations of airborne mold spores or related agents of microbial origin. We included in meta-analyses only the studies with reports of dampness and/or mold as risk factors ${ }^{1}$. A large majority of all studies used these risk factors. We did not distinguish among dampness, mold, dampness or mold, and dampness and mold as risk factors. Our rationale - visible mold is always considered the result of excess dampness, whether or not the dampness is reported, and excess dampness is very often 
Table 1. Health outcomes from reviewed studies, grouped into outcome categories used in meta-analysis

\begin{tabular}{|c|c|}
\hline $\begin{array}{l}\text { Outcome } \\
\text { Category for } \\
\text { the Meta- } \\
\text { Analysis }\end{array}$ & Outcomes from Individual Studies Used in Each Category \\
\hline $\begin{array}{l}\text { Upper } \\
\text { respiratory } \\
\text { tract (URT) } \\
\text { symptoms }\end{array}$ & $\begin{array}{l}\text { irritated, stuffy, or runny nose; nasal symptom; nasal congestion; nasal congestion or } \\
\text { runny nose; nasal excretion; nose irritation; rhinitis; sinusitis; allergic rhinitis; allergy; } \\
\text { hay fever }\end{array}$ \\
\hline Cough & $\begin{array}{l}\text { cough; cough with phlegm; cough without phlegm; day or night cough; dry cough; } \\
\text { morning cough; long-term cough; night cough with wheeze; persistent cough }\end{array}$ \\
\hline Wheeze & $\begin{array}{l}\text { wheeze; persistent wheeze; wheeze apart from cold; wheeze including shortness of } \\
\text { breath and asthma; wheeze/breathlessness }\end{array}$ \\
\hline $\begin{array}{l}\text { Ever } \\
\text { diagnosed } \\
\text { with asthma }\end{array}$ & $\begin{array}{l}\text { - positive response to -- has a doctor ever diagnosed mother (father) to have attacks } \\
\text { of shortness of breath (asthma); } \\
\text { - } \quad \text { positive response to-- did a doctor ever diagnose your having attacks of shortness } \\
\text { of breath or asthma?; } \\
\text { - physician-diagnosed asthma; } \\
\text { - physician-diagnosed asthma, ever (atopic and non-atopic); } \\
\text { - } \quad \text { physician diagnosis of asthma since age }>16 \text {; } \\
\text { - } \quad \text { self-reported physician-diagnosed or nurse-diagnosed asthma }\end{array}$ \\
\hline $\begin{array}{l}\text { Current } \\
\text { asthma }\end{array}$ & $\begin{array}{l}\text { - current physician-diagnosed asthma, defined as diagnosis plus symptoms in last } 12 \\
\text { months; } \\
\text { - ever doctor-diagnosed asthma plus asthma symptoms or medication in past } 12 \\
\text { months; } \\
\text { current asthma defined as combination of bronchial hyper-responsiveness and at } \\
\text { least one of wheeze or breathlessness in last } 12 \text { months; } \\
\text { - subjective symptoms of asthma plus one or more of the following: doctor } \\
\text { diagnosed asthma attack and the disappearance of wheezing; doctor diagnosed } \\
\text { asthma attack and }>15 \% \text { decrease in PEF or FEV1; }>15 \% \text { decrease in PEF or } \\
\text { FEV1 in exercise test; }>20 \% \text { daily variation in PEF at least } 2 \text { days per week in } 4 \\
\text { weeks of tracking; }>15 \% \text { rise in PEF or FEV1 in a bronchodilating test; } \\
\text { - asthma - current and diagnosed by physician; } \\
\text { - current asthma diagnosed by a doctor -- text implies that current refers to the last } \\
\text { - } 12 \text { months; } \\
\text { - asthma currently present and reported to be confirmed by a physician; } \\
\text { occurrence of doctor diagnosed asthma in past year; } \\
\text { positive response to following two questions -- has your doctor ever said your } \\
\text { child has asthma? does he or she still have asthma? }\end{array}$ \\
\hline $\begin{array}{l}\text { Asthma } \\
\text { development }\end{array}$ & $\begin{array}{l}\text { - newly doctor-diagnosed cases of asthma in past } 2.5 \text { years; } \\
\text { - } \quad \text { physician diagnosis of asthma since age }>16 \\
\text { - } \quad \text { first time diagnosis of asthma }\end{array}$ \\
\hline
\end{tabular}

accompanied by mold, although the mold may not be visible. Thus, it is not possible to make a clean distinction among these risk factors. We excluded from the meta-analyses ORs from

\footnotetext{
${ }^{2}$ The question's wording reflects the fact that the study assessed the risk of asthma in mothers and fathers of school children as a function of dampness in the home as part of a broader study focusing on children's asthma symptoms
} 
studies with measured concentrations of microbial agents or measured or reported high air humidity (Appendix 2).

Presence of dampness and/or mold were made in each study by either the occupants or the researchers. We did not distinguish between occupant-reported dampness and/or mold and researcher-reported dampness and/or mold. Most studies that have compared occupant reports and researcher reports of dampness and/or mold have found the two types of reports to be fairly well correlated. Also, whether or not researcher-based reports are more accurate is still a subject of debate.

The large majority of studies have assessed the risks of dampness and/or mold in homes. ORs associated with dampness and/or mold in other types of buildings, such as schools or work places, were excluded from our analyses (Appendix 2).

Health outcome categories

For the non-asthma outcomes of upper respiratory tract (URT) symptoms, cough, and wheeze (Table 1), we categorized the health outcomes as in the IOM report (IOM 2004). The URT symptom category included the broadest set of health outcomes, but nasal symptoms predominated.

For asthma outcomes, however, based on review of the original papers, we developed different outcome categories than were used in the IOM report (IOM 2004). Our asthma development category included ORs from studies that attempted to assess whether the development of asthma, as opposed to presence of asthma symptoms, was associated with dampness and mold; however, the associated time period for the asthma diagnosis or development ranged widely and there were few studies in this category.

Several studies were excluded from meta-analyses because of outcomes used (Appendix 2). For the asthma diagnosis and development categories, we excluded ORs from Wever-Hess et al. (2000) and Oie et al. (1999), with outcomes of asthma diagnosis or bronchial obstruction in children with an age less than 2 , because it is not clear that asthma can be diagnosed before age 2. We excluded results from a single study performed in rural Kenya (Mohamad et al. 1995) because the living and health care conditions in this study population were distinctively different from those in other studies. The ORs from Pihronen et al (1996) were also excluded because they indicated the odds of having one or more of a diverse set of outcomes (asthma, hay fever, allergic rhinitis, or eczema).

$\underline{\text { Statistical methods }}$

Some of the reviewed studies reported separate estimates for multiple outcomes within the same subjects in the same study. Because these findings within the same study may not be statistically "independent," ignoring this dependence within a meta-analysis might overestimate the number of truly independent inputs to the summary model, and thus overestimate the precision of the summary estimates produced. These meta-analyses use "random effect" models, which assume a single fixed mean effect (i.e., the association between the risk and the outcome in each model) across all studies, plus a random component that varies across studies or sub-studies. Random effect models can estimate any within-study correlations included in the meta-analysis, and 
adjust the estimates produced as necessary. Such adjustment makes little difference in point estimates, but may increase the confidence interval for estimates. We used the SAS procedure PROC MIXED, which allows fixing the within-study variances (matrix $R$ in SAS) while estimating between-study variance (matrix $G$ in SAS) at a different level.

The odds ratios and $95 \%$ confidence intervals reported in each reviewed study were first transformed to the log scale. The transformed results were then combined using a random effect model (DerSimonian \& Laird, 1986). Models were constructed both accounting for the correlation between multiple results within studies ("dependent sub-studies"), and ignoring such potential correlation ("independent sub-studies").

The model for independent sub-studies was

$$
y_{i j} \sim N\left(\beta_{0}+\beta_{0 i j}, \sigma_{i j}^{2}\right)
$$

The model for dependent sub-studies was

$$
y_{i j} \sim N\left(\beta_{0}+\beta_{0 i}, \sigma_{i j}^{2}\right)
$$

where:

$y_{i j}$ is the $\ln$ OR in $j$ th sub-study of $i$ th study;

$\beta_{0}$ is the fixed effect across all studies;

$\beta_{0 i j}$ is the random effect in the $j$ th sub-study of the ith study;

$\beta_{0 i j} \sim N\left(0, \sigma^{2}\right) ; \sigma^{2}$ is the between-sub-study variance;

$\beta_{0 i}$ :is the random effect in the ith study. $\beta_{0 i} \sim N\left(0, \sigma^{* 2}\right)$;

$\sigma^{* 2}$ is the between-study variance; and

$\sigma_{i j}^{2}$ is the within-study variance, calculated from log confidence interval.

\section{RESULTS}

Major results of the meta-analyses are summarized in Table 2. (Appendix 3 shows, as an example, ORs and CIs for the association of wheeze with dampness and mold in the original studies, and also from the summary estimates produced in the meta-analysis.) Central estimates of ORs ranged from 1.32 to 2.10 , with most central estimates between 1.3 and 1.8. Confidence intervals (95\%) excluded unity for 26 of 28 analyses, and in most cases the lower bound of the $\mathrm{CI}$ exceeded 1.2. In general, the two meta-analysis methods produced similar estimates for ORs and CIs. ORs for health effects in children were not consistently larger or smaller than corresponding ORs for adults. CIs tended to be smaller for analyses including both adults and children, presumably because of the larger numbers of studies. CIs for asthma development were broad, with lower bounds near unity, presumably because the analyses included data from only three studies. 
Table 2. Key results of the meta-analyses

\begin{tabular}{|c|c|c|c|c|}
\hline Outcome & Subjects & $\begin{array}{c}\text { \# of } \\
\text { Studies }\end{array}$ & $\begin{array}{c}\text { Odds Ratio } \\
\text { Random-Effect Model } \\
\text { Dependent } \\
\text { Sub-studies }\end{array}$ & $\begin{array}{c}\text { Odds Ratio } \\
\text { Random-Effect Model } \\
\text { Independent } \\
\text { Sub-studies }\end{array}$ \\
\hline \multirow{3}{*}{$\begin{array}{l}\text { Upper } \\
\text { respiratory } \\
\text { tract } \\
\text { symptoms }\end{array}$} & All & 10 & $1.53(1.26-1.87)$ & $1.54(1.33-1.78)$ \\
\hline & Adults & 6 & $1.39(1.12-1.71)$ & $1.37(1.17-1.59)$ \\
\hline & Children & 4 & $1.92(1.08-3.41)$ & $2.04(1.41-2.96)$ \\
\hline \multirow{3}{*}{ Cough } & All & 19 & $1.77(1.47-2.12)$ & $1.79(1.57-2.03)$ \\
\hline & Adults & 5 & $2.10(1.27-3.47)$ & $2.04(1.55-2.68)$ \\
\hline & Children & 14 & $1.62(1.35-1.94)$ & $1.65(1.44-1.88)$ \\
\hline \multirow{3}{*}{ Wheeze } & All & 16 & $1.81(1.45-2.26)$ & $1.65(1.48-1.83)$ \\
\hline & Adults & 3 & $1.68(1.14-2.49)$ & $1.66(1.42-1.95)$ \\
\hline & Children & 13 & $1.91(1.42-2.57)$ & $1.65(1.43-1.90)$ \\
\hline \multirow{3}{*}{$\begin{array}{l}\text { Current } \\
\text { asthma }\end{array}$} & All & 10 & $1.51(1.40-1.62)$ & 1.51 (1.41-1.61) \\
\hline & Adults & 3 & $1.82(1.28-2.59)$ & $1.82(1.52-2.19)$ \\
\hline & Children & 7 & $1.45(1.33-1.58)$ & $1.45(1.34-1.57)$ \\
\hline $\begin{array}{c}\text { Ever } \\
\text { diagnosed } \\
\text { asthma } \\
\end{array}$ & All & 8 & $1.59(1.26-2.00)$ & $1.70(1.42-2.04)$ \\
\hline $\begin{array}{c}\text { Asthma } \\
\text { development }\end{array}$ & All & 3 & $1.39(0.69-2.80)$ & $1.32(.98-1.77)$ \\
\hline
\end{tabular}

\section{DISCUSSION}

Importance of building dampness

Based on the meta-analyses described in this report, building dampness and mold are associated with $30 \%$ to $80 \%$ increases $^{3}$ in a variety of health outcomes in a variety of populations. These associations are statistically significant - with $95 \%$ CIs excluding unity -- in almost all cases. The similar results obtained from two analysis methods suggest little problem with correlation of health outcomes within studies. Statistical associations do not prove that dampness and mold are causally related to the health outcomes. Building dampness itself is very unlikely to directly cause adverse health effects. However, the consistent and relatively strong associations of dampness with adverse health effects strongly suggest causation by dampness-related exposures. Building dampness may cause the building to become contaminated with microorganisms such

\footnotetext{
${ }^{3}$ The $30 \%$ to $80 \%$ increase in symptoms is an approximate estimate based on the central estimates of the ORs for the various health outcomes in Table 2 . When the health outcome prevalence is below approximately $15 \%$, which is typically the case for wheeze and asthma-related outcomes, the percentage increase in the outcome among the population experiencing the risk factor (e.g., dampness) is well estimated by $100 \%(1-\mathrm{OR})$. The central estimates of ORs for these health outcomes ranges from 1.32 to 1.91 , implying a $33 \%$ to $91 \%$ increase in health outcome prevalence. However, when the prevalence of the outcome is substantially higher than $15 \%$, as is often the case for URT symptoms and cough, this simple calculation overestimates the percentage increase in the outcome in the population with the risk factor. For example, assuming an outcome prevalence of 0.3 for URT symptoms and cough in the population with dampness, the OR in Table 2 of 1.79 for cough indicates a $53 \%$ increase in cough among the exposed population and the OR of 1.54 in Table 2 for URT symptoms indicates a $38 \%$ increase in URT symptoms among the exposed population.
} 
as mold or bacteria, which might in-turn cause adverse health effects (IOM 2004). Building dampness could also cause increased emissions of some chemical pollutants from materials and surfaces (IOM 2004). Research has not yet determined the causal agent(s) (IOM 2004).

Implication of building dampness as a public health problem requires that the presence of building dampness increase health risks, and also that a substantial proportion of the population is exposed to dampness. Most available data indicate that at least $20 \%$ of homes have dampness problems or visible mold (IOM 2004). In addition, the adverse consequences of building dampness go beyond health effects and the related personal and economic costs. Dampness causes structural damage to buildings that is expensive to repair. Also, mold contamination resulting from building dampness often precipitates very expensive remediation efforts (Levin 2005).

Despite the current lack of proof that dampness or mold actually causes these health effects, available knowledge suggests that it is prudent to prevent building dampness and mold and to take corrective actions where such conditions occur (IOM 2004). Many of the preventive and corrective actions are straightforward. Examples include better training of those in the construction industry about the means of reducing dampness risks and instituting ongoing preventive maintenance programs to identify and quickly remedy roof and plumbing leaks or other causes of moisture accumulation or mold growth.

\section{Limitations in this analysis}

These meta-analyses used data only from studies referenced in the IOM's recent critical review (IOM 2004), and, thus, omitted more recently published studies. However, as research on dampness and mold has occurred for over two decades, it is unlikely that studies published in the last few years (i.e., since 2003) would substantially affect the outcomes of our meta-analyses.

Because our meta-analyses used only studies cited in the IOM's review, we have effectively relied on the IOM to select studies of suitable quality. All original studies were published in refereed archival journals, which is one indicator of study quality. The IOM did not precisely describe other study selection criteria, but in general their reviews consider only studies without significant evident methodological flows, with control for major known confounding factors via the study design or method of data analysis, and with a statistical analysis of study data. Remaining errors from any confounding and bias in the reviewed studies may be reflected in results of the meta-analyses, although some of these, due to the combination of different studies, may cancel out and have a modest impact on results of the meta-analyses.

One potential source of bias pertains to the methods used to determine whether a building had dampness or mold. Most studies have relied on the occupants to report whether dampness or mold is present in their home. It is possible that homeowners with respiratory health problems would be more aware of, and thus, more likely to report dampness and mold than homeowners without such health problems. If true, this reporting bias would lead to overestimated ORs in the original studies and corresponding overestimated ORs from our meta-analyses. On the other hand, as homeowners within each study would report dampness or mold in a relatively unstandardized way, the resulting random error in assessment could result in what is called "nondifferential exposure misclassification," leading to underestimated ORs in those studies. 
Alternately, some studies have relied on trained surveyors who inspected buildings for signs of dampness and mold. Surveyors would have used standardized methods of assessment for dampness or mold within each study, thus reducing that source of inaccuracy. Surveyors, however, are likely to have missed indicators of dampness and mold that were not present or evident during their brief survey, leading to random errors in exposure assessment and consequent underestimates of any true risk. In general, both types of studies have found increased risks of respiratory health effects among occupants of homes with dampness and molds. Unfortunately, we do not have a sufficient number of studies with surveyor-assessed dampness and mold to enable separate meta-analyses.

Reviews and meta-analyses are also subject to publication bias - the overestimation of summary estimates of association that can occur because studies with positive findings are published more often (IOM 2004, pg 20) and more quickly than studies that failed to find significant associations. Publication bias would bias the results of our meta-analyses upward; i.e., estimated ORs based on all published studies would exceed true central estimates based on all performed studies. While there are statistical tools available that enable one to check for evidence of publication bias, it remains difficult to quantify the extent of publication bias or to make corrections in the resulting central estimates of ORs.

It is important to note that the confidence intervals associated with our central estimates of ORs reflect only the probabilistic or chance uncertainties. The full uncertainties in the magnitudes of increased health risks are likely to be larger because they would also include the potential uncontrolled confounding and bias noted above.

\section{Asthma development -- comparison to findings of IOM}

The IOM Committee found limited or suggestive evidence of an association between building dampness and asthma development, and inadequate or insufficient evidence to determine whether an association exists between mold and asthma development. These statements are consistent with the results of our meta-analysis. We calculated ORs of 1.32 and 1.39 for asthma development if the home had dampness or mold; however, neither CI excluded unity. Also, our meta analysis for asthma development was based on only three studies and the definitions for asthma development used in these three studies were variable.

\section{CONCLUSIONS}

Based on our meta-analyses, building dampness and mold are associated with $30 \%$ to $80 \%$ increases in a variety of respiratory and asthma-related health outcomes and the associations are statistically significant in nearly all cases. Given what is known today, it would be prudent to avoid building dampness and mold problems and to take corrective actions where such problems occur.

\section{ACKNOWLEDGMENTS}


This work was also supported by the Indoor Environments Division, Office of Radiation and Indoor Air, Office of Air and Radiation of the U.S. Environmental Protection Agency through interagency agreement DW-89-92175001-0 with the U.S. Department of Energy. The authors would like to thank Phil Price, and David Mudarri and his colleagues at EPA, for their valuable comments on a draft document.

\section{REFERENCES}

Andriessen J, Brunekreef B, Roemer W. 1998. Home dampness and respiratory health status in European children. Clinical and Experimental Allergy 28:1191-1200.

Austin JB, Russell G. 1997. Wheeze, cough, atopy, and indoor environment in the Scottish Highlands. Archives of Disease in Childhood 76(1):22-26.

Belanger K, Beckett W, Triche E, Bracken MB, Holford T, Ren P, McSharry JE, Gold DR, Platts-Mills TA, Leaderer BP. 2003. Symptoms of wheeze and persistent cough in the first year of life: associations with indoor allergens, air contaminants, and maternal history of asthma. American Journal of Epidemiology 158(3):195-202.

Brunekreef B, Dockery DW, Speizer FE, Ware JH, Spengler JD, Ferris BG. 1989. Home dampness and respiratory morbidity in children. American Review of Respiratory Disease 140(5):1363-1367.

Brunekreef B. 1992. Damp housing and adult respiratory symptoms. Allergy 47(5):498-502.

Dales RE, Burnett R, Zwanenburg H. 1991. Adverse health effects among adults exposed to home dampness and molds. American Review of Respiratory Disease 143(3):505-509.

Dales RE, Miller D. 1999. Residential fungal contamination and health: microbial cohabitants as covariates. Environmental Health Perspectives 107(Supplement 3):481-483.

Dales R, Miller D, White J. 1999. Testing the association between residential fungus and health using ergosterol measures and cough recordings. Mycopathologia 147:21-27.

Dales R, Zwanenburg H, Burnett R, Franklin C. 1991. Respiratory health effects of home dampness and molds among Canadian children. American Journal of Epidemiology 134(2):196-203.

Dekker C, Dales R, Bartlett S, Brunekreff B, Zwanenburg H. 1991. Childhood asthma and the indoor environment. Chest 100:922-926.

DerSimonian R, Laird N. 1986. Meta-analysis in clinical trials. Controlled Clin Trials 7: 177188.

Dijkstra L, Houthuijs D, Brunekreff B, Akkerman I, Boleij J. 1990. Respiratory health effects of the indoor environment in a population of Dutch children. American Review of Respiratory Disease 142:1172-1178.

Engvall K, Norrby C, Norbäck D. 2001. Asthma symptoms in relation to building dampness and odour in older multifamily houses in Stockholm. International Journal of Tuberculosis and Lung Disease 5(5):468-477.

Engvall K, Norrby C, Norbäck D. 2002. Ocular, airway, and dermal symptoms related to building dampness and odors in dwellings. Archives of Environmental Health 57(4):304-310.

Gent JF, Ren P, Belanger K, Triche E, Bracken MB, Holford TR, Leaderer BP. 2002. Levels of household mold associated with respiratory symptoms in the first year of life in a cohort at risk for asthma. Environmental Health Perspectives 110(12):A781-A786. 
Gunnbjörnsdottir MI, Norbäck D, Plaschke P, Norrman E, Björnsson E, Janson C. 2003. The relationship between indicators of building dampness and respiratory health in young Swedish adults. Respiratory Medicine 97(4):302-307.

Hu F, Persky V, Flay B, Phil D, Richardson PH. 1997. An epidemiological study of asthma prevalence and related factors amoung young adults. Journal of Asthma 34(1):67-76.

Infante-Rivard C. 1993. Childhood asthma and indoor environmental risk factors. American Journal of Epidemiology 137(8):834-844.

IOM (Institute of Medicine) 2004. Damp indoor spaces and health. Washington, DC: National Academy Press.

Jaakkola JJ, Jaakkola N, Ruotsalainen R. 1993. Home dampness and molds as determinants of respiratory symptoms and asthma in pre-school children. Journal of Exposure Analysis and Environmental Epidemiology 3(Supplement 1):129-142.

Jaakkola MS, Nordman H, Piipari R, Uitti J, Laitinen J, Karjalainen A, Hahtola P, Jaakkola JJ. 2002. Indoor dampness and molds and development of adult-onset asthma: a population-based incident casecontrol study. Environmental Health Perspectives 110(5):543-547.

Jędrychowski W, Flak E. 1998. Separate and combined effects of the outdoor and indoor air quality on chronic respiratory symptoms adjusted for allergy among preadolescent children. International Journal of Occupational Medicine and Environmental Health 11(1):19-35.

Kilpeläinen M, Terho EO, Helenius H, Koskenvuo M. 2001. Home dampness, current allergic diseases, and respiratory infections among young adults. Thorax 56(6):462-467.

Koskinen OM, Husman TM, Meklin TM, Nevalainen AI. 1999a. Adverse health effects in children associated with moisture and mold observations in houses. International Journal of Environmental Health Research 9(2):143-156.

Koskinen OM, Husman TM, Meklin TM, Nevalainen AI. 1999b. The relationship between moisture or mould observations in houses and the state o health of their occupants. European Respiratory Journal 14(6):1363-1367.

Levin H 2005. National expenditures for iaq problem prevention or mitigation. LBNL-58694. Lawrence Berkeley National Laboratory Report, Berkeley, CA.

Maier WC, Arrighi HM, Morray B, Llewellyn C, Redding GJ. 1997. Indoor risk factors for asthma and wheezing among Seattle school children. Environmental Health Perspectives 105(2):208-214.

Mohamed N, Ng'ang'a L, Odhiambo J, Nyamwaya J, Menzies R. 1995. Home environment and asthma in Kenyan schoolchildren: a case-control study. Thorax 50(1):74-78.

Nafstad P, Øie L, Mehl R, Gaarder P, Lodrup-Carlsen K, Botten G, Magnus P, Jaakkola J. 1998. Residential dampness problems and symptoms and signs of bronchial obstruction in young Norwegian children. American Journal of Respiratory and Critical Care Medicine 157:410-414.

Nicolai T, Illi S, von Mutius E. 1998. Effect of dampness at home in childhood on bronchial hyperreactivity in adolescence. Thorax 53(12):1035-1040.

Norbäck D, Björnsson E, Janson C, Palmgren U, Boman G. 1999. Current asthma and biochemical signs of inflammation in relation to building dampness in dwellings. International Journal of Tuberculosis and Lung Disease 3(5):368-376.

Øie L, Nafstad P, Botten G, Magnus P, Jaakkola J. 1999. Ventilation in homes and bronchial obstruction in young children. Epidemiology 10(3):294-299. 
Park JH, Gold DR, Spiegelman DL, Burge HA, Milton DK. 2001. House dust endotoxin and wheeze in the first year of life. American Journal of Respiratory and Critical Care Medicine 163(2):322-328.

Pirhonen I, Nevalainen A, Husman T, Pekkanen J. 1996. Home dampness, moulds and their influence on respiratory infections and symptoms in adults in Finland. European Respiratory Journal 9(12):26182622.

Rönmark E, Jönsson E, Platts-Mills T, Lundbäck B. 1999. Different pattern of risk factors for atopic and nonatopic asthma among children - report from the Obstructive Lung Disease in Northern Sweden Study. Allergy 54(9):926-935.

Rylander R, Mégevand Y. 2000. Environmental risk factors for respiratory infections. Archives of Environmental Health 55(5):300-303.

Rylander R, Norrhall M, Engdahl E, Tunsäter A, Holt P. 1998. Airways inflammation, atopy, and (1 $\rightarrow 3)$ $\beta$-D-glucan exposure in two schools. American Journal of Respiratory and Critical Care Medicine 158:1685-1687.

Slezak JA, Persky VW, Kviz FJ, Ramakrishnan V, Byers C. 1998. Asthma prevalence and risk factors in selected Head Start sites in Chicago. Journal of Asthma 35(2):203-212.

Strachan DP, Flannigan B, McCabe EM, McGarry F. 1990. Quantification of airborne moulds in the homes of children with and without wheeze. Thorax 45(5):382-387.

Taskinen T, Hyvärinen A, Meklin T, Husman T, Nevalainen A, Korppi M. 1999. Asthma and respiratory infections in school children with special reference to moisture and mold problems in the school. Acta Pædiatrica 88(12):1373-1379.

Thorn J, Brisman J, Torén K. 2001. Adult-onset asthma is associated with self-reported mold or environmental tobacco smoke exposures in the home. Allergy 56(4):287-292.

Thorn J, Rylander R. 1998a. Airways inflammation and glucan in a rowhouse area. American Journal of Respiratory and Critical Care Medicine 157(6 Pt 1):1798-1803.

Verhoeff AP, van Strien RT, van Wijnen JH, Brunekreef B. 1995. Damp housing and childhood respiratory symptoms: the role of sensitization to dust mites and molds. American Journal of Epidemiology 141(2):103-110.

Waegemaekers M, van Wageningen N, Brunekreef B, Boleij JS. 1989. Respiratory symptoms in damp homes. A pilot study. Allergy 44(3):192-198.

Wan GH, Li CS. 1999. Dampness and airway inflammation and systemic symptoms in office building workers. Archives of Environmental Health 54(1):58-63.

Wieslander G, Norbäck D, Nordstrom K, Wålinder R, Venge P. 1999. Nasal and ocular symptoms, tear film stability, and biomarkers in nasal lavage, in relation to building-dampness and building design in hospitals. International Archives of Occupational and Environmental Health 72(7):451-461.

Wever-Hess J, Kouwenberg J, Duiverman EJ, Hermans J, Wever A. 2000. Risk factors for exacerbations and hospital admissions in asthma of early childhood. Pediatric Pulmonology 29:250-256.

Williamson IJ, Martin C, McGill G, Monie RDH, Fennery AG. 1997. Damp housing and asthma: a casecontrol study. Thorax 52(3):229-234.

Yazicioglu M, Saltik A, Öne Ü, Sam A, Ekerbiçer HÇ, Kirçuval O. 1998. Home environment and asthma in school children from the Edire region in Turkey (Factores ambientales y asma en escolares de la región de Edirne, Turquía). Allergy and Immunopathology (Allergologia et Immunopathologia) 26(1):5-8. 
Yang CY, Chiu JF, Chiu HF, Kao WY. 1997. Damp house conditions and respiratory symptoms in primary school children. Pediatric Pulmonology 24(2):73-77.

Yang CY, Tien YC, Hsieh HJ, Kao WY, Lin MC. 1998. Indoor environmental risk factors and childhood asthma: a case-control study in a subtropical area. Pediatric Pulmonology 26(2):120-124.

Zacharasiewicz A, Zidek T, Haidinger G, Waldhör T, Vutuc C, Zacharasiewicz A, Goetz M, Pearce N. 2000. Symptoms suggestive of atopic rhinitis in children aged 6-9 years and the indoor environment. Allergy 55(10):945-950.

Zock JP, Kogevinas M, Sunyer J, Jarvis D, Toren K, Anto JM; European Community Respiratory Health Survey. 2002. Housing characteristics, reported mold exposure, and asthma in the European Community Respiratory Health Survey. Journal of Allergy and Clinical Immunology 20(3):285-292. 


\section{Appendix 1. Description of studies included in the meta-analyses.}

Table A1.1 Studies with upper respiratory tract symptoms

\begin{tabular}{|c|c|c|c|c|}
\hline Subjects & Author & Year & Risk Factor & Symptomx \\
\hline \multirow{8}{*}{ adults } & Engvall & 2002 & moldy odor \& water leakage in preceding 5 years & nasal \\
\hline & \multirow{4}{*}{ Koskinen } & \multirow{4}{*}{1999} & \multirow{2}{*}{ surveyor assessed moisture } & rhinitis \\
\hline & & & & sinusitis \\
\hline & & & \multirow{2}{*}{ mold } & rhinitis \\
\hline & & & & sinusitis \\
\hline & \multirow{2}{*}{ Wan } & \multirow{2}{*}{1999} & flood & \multirow{2}{*}{ nasal congestion or runny nose } \\
\hline & & & mold & \\
\hline & Wieslander & 1999 & damp concrete floor & irritated, stuffy, or runny nose \\
\hline men & \multirow{2}{*}{ Brunekreef } & \multirow{2}{*}{1992} & \multirow{2}{*}{ damp stains or mold growth in last 2 years } & \multirow{2}{*}{ allergy } \\
\hline women & & & & \\
\hline \multirow{10}{*}{ children } & \multirow{2}{*}{ Brunekreef } & \multirow{2}{*}{1989} & damp ever & \multirow{2}{*}{ hay fever } \\
\hline & & & mold ever & \\
\hline & \multirow{4}{*}{ Jaakkola } & \multirow{4}{*}{1993} & \multirow{2}{*}{ mold odor in past year } & nasal congestion \\
\hline & & & & nasal excretion \\
\hline & & & \multirow{2}{*}{ water damage $>1$ year ago } & nasal congestion \\
\hline & & & & nasal excretion \\
\hline & \multirow{2}{*}{ Koskinen } & \multirow{2}{*}{1999} & \multirow{2}{*}{ surveyor assessed moisture } & rhinitis \\
\hline & & & & sinusitis \\
\hline & Zacharasiewicz & 2000 & damp & nasal \\
\hline & Kilpeläinen & 2001 & visible mold & allergic rhinitis \\
\hline students & Kilpeläinen & 2001 & visible mold or damp stains or water damage & allergic rhinitis \\
\hline
\end{tabular}


Table A1.2 Studies with cough as an outcome

\begin{tabular}{|c|c|c|c|c|}
\hline Subjects & Author & Year & Risk & Health outcome \\
\hline \multirow{10}{*}{ adults } & Engvall & 2001 & moldy odor \& major water leakage & cough \\
\hline & Engvall & 2001 & moldy odor \& signs of hi humidity & cough \\
\hline & Gunnbjörnsdottir & 2003 & water damage or mold & long-term cough \\
\hline & Koskinen & 1999 & moisture & cough w/phlegm \\
\hline & Koskinen & 1999 & moisture & cough w/o phlegm \\
\hline & Koskinen & 1999 & moisture & night cough \\
\hline & Koskinen & 1999 & mold & cough w/phlegm \\
\hline & Koskinen & 1999 & mold & cough w/o phlegm \\
\hline & Koskinen & 1999 & mold & night cough \\
\hline & Pirhonen & 1996 & mold or damp & cough \\
\hline \multirow{4}{*}{$\begin{array}{l}\text { men } \\
\text { men } \\
\text { women } \\
\text { women }\end{array}$} & Brunekreef & 1992 & damp stains or mold growth last 2 yrs & cough \\
\hline & \begin{tabular}{|l|} 
Waegemaekers \\
\end{tabular} & 1989 & damp & cough \\
\hline & Brunekreef & 1992 & damp stains or mold growth last 2 yrs & cough \\
\hline & Waegemaekers & 1989 & damp & cough \\
\hline \multirow[b]{25}{*}{ L. } & Andriessen & 1998 & moisture stains & cough \\
\hline & Andriessen & 1998 & mold & cough \\
\hline & Austin & 1997 & damp & cough \\
\hline & Austin & 1997 & mold & cough \\
\hline & Brunekreef & 1989 & damp ever & cough \\
\hline & Brunekreef & 1989 & mold ever & cough \\
\hline & Dales & 1991 & flood & cough \\
\hline & Dales & 1991 & moisture & cough \\
\hline & Dales & 1991 & Mold site & cough \\
\hline & Dales & 1991 & Mold sites & cough \\
\hline & Dales & 1991 & mold or damp & cough \\
\hline & Dales & 1999 & mold or mildew & night cough or wheeze \\
\hline & Dijkstra & 1990 & mold \& damp & cough \\
\hline & \begin{tabular}{|l|} 
Dijkstra \\
\end{tabular} & 1990 & mold or damp & cough \\
\hline & \begin{tabular}{|l|} 
Jaakkola \\
\end{tabular} & 1993 & mold odor past yr & persistent cough \\
\hline & \begin{tabular}{|l|} 
Jaakkola \\
\end{tabular} & 1993 & water damage $>1$ yr ago & persistent cough \\
\hline & \begin{tabular}{|l|} 
Jedrychowski \\
\end{tabular} & 1998 & mold or damp & cough \\
\hline & \begin{tabular}{|l|} 
Koskinen \\
\end{tabular} & 1999 & moisture & cough w/ phlegm \\
\hline & Koskinen & 1999 & moisture & cough w/o phlegm \\
\hline & Koskinen & $1999 \mathrm{~b}$ & moisture & night cough \\
\hline & Verhoeff & 1995 & damp & cough \\
\hline & \begin{tabular}{|l|} 
Verhoeff \\
\end{tabular} & 1995 & mold & cough \\
\hline & \begin{tabular}{|l|} 
Waegemaekers \\
\end{tabular} & 1989 & damp & day or night cough \\
\hline & Waegemaekers & 1989 & damp & morning cough \\
\hline & Gent & 2002 & water leaks & cough \\
\hline $\begin{array}{l}\text { infants w/ asthmatic sibling + } \\
\text { asthmatic mother }\end{array}$ & \multirow{2}{*}{ Belanger } & \multirow{2}{*}{2003} & \multirow{2}{*}{$\begin{array}{l}\text { persistent mold or mildew previous } \\
\text { year }\end{array}$} & \multirow{2}{*}{ persistent cough } \\
\hline $\begin{array}{l}\text { infants w/ asthmatic sibling + } \\
\text { non-asthmatic mother } \\
\end{array}$ & & & & \\
\hline adolescents & Nicolai & 1998 & past or present damp & cough \\
\hline
\end{tabular}


Table A1.3 Studies with wheeze as an outcome.

\begin{tabular}{|c|c|c|c|c|}
\hline Subjects & Author & Year & Risk & Outcome \\
\hline \multirow{6}{*}{ adults } & Gunnbjörnsdottir & 2003 & water damage or mold & wheeze \\
\hline & \multirow{5}{*}{ Norbäck } & \multirow{5}{*}{1999} & $>1$ signs of dampness & \multirow{5}{*}{ wheeze } \\
\hline & & & damp floor & \\
\hline & & & visible mold on indoor surfaces & \\
\hline & & & moldy odor & \\
\hline & & & water damage or flood & \\
\hline \multirow{2}{*}{ men } & Brunekreef & 1992 & damp stains or mold growth in last 2 yrs & wheeze \\
\hline & Waegemaekers & 1989 & damp & wheeze \\
\hline \multirow{2}{*}{ women } & Brunekreef & 1992 & damp stains or mold growth in last 2 yrs & wheeze \\
\hline & Waegemaekers & 1989 & damp & wheeze \\
\hline \multirow{21}{*}{ children } & \multirow{2}{*}{ Brunekreef } & 1989 & damp ever & wheeze \\
\hline & & 1989 & molds ever & wheeze \\
\hline & \multirow{5}{*}{ Dales } & \multirow{5}{*}{1991} & flood & \multirow{5}{*}{ wheeze } \\
\hline & & & moisture & \\
\hline & & & mold site & \\
\hline & & & mold sites & \\
\hline & & & mold or damp & \\
\hline & \multirow{2}{*}{ Dijkstra } & \multirow{2}{*}{1990} & mold \& damp & \multirow{2}{*}{ wheeze } \\
\hline & & & mold or damp & \\
\hline & \multirow{2}{*}{ Jaakkola } & \multirow{2}{*}{1993} & mold odor in past year & \multirow{2}{*}{$\begin{array}{l}\text { persistent } \\
\text { wheeze }\end{array}$} \\
\hline & & & water damage $>1 \mathrm{yr}$ ago & \\
\hline & Jedrychowski & 1998 & mold or damp & wheeze \\
\hline & \multirow{5}{*}{ Maier } & \multirow{5}{*}{1997} & basement water & \multirow{5}{*}{ wheeze } \\
\hline & & & mold & \\
\hline & & & $\begin{array}{l}\text { mold, water damage, basement water, or water } \\
\text { condensation }\end{array}$ & \\
\hline & & & water condensation & \\
\hline & & & water damage & \\
\hline & Slezak & 1998 & mold or damp & wheeze \\
\hline & Strachan & 1990 & mold & wheeze \\
\hline & Taskinen & 1999 & damp & wheeze \\
\hline & Waegemaekers & 1989 & damp & wheeze \\
\hline infants w/ asthmatic sibling & Gent & 2002 & Water leaks & wheeze \\
\hline $\begin{array}{l}\text { infants w/ asthmatic sibling } \\
+ \text { asthmatic mother }\end{array}$ & \multirow{2}{*}{ Belanger } & \multirow{2}{*}{2003} & \multirow{2}{*}{ persistent mold or mildew in previous year } & \multirow{2}{*}{ wheeze } \\
\hline $\begin{array}{l}\text { infants } \mathrm{w} / \text { asthmatic sibling, } \\
+ \text { nonasthmatic mother }\end{array}$ & & & & \\
\hline \multirow{2}{*}{ adolescent } & \multirow{2}{*}{ Nicolai } & \multirow{2}{*}{1998} & damp & \multirow{2}{*}{ wheeze } \\
\hline & & & damp, adjusted for mite allergen concentration & \\
\hline
\end{tabular}


Table A1.4 Studies with asthma diagnosis as an outcome.

\begin{tabular}{|c|c|c|c|c|}
\hline Subjects & Author & Year & Risk & Outcome description* \\
\hline \multirow{8}{*}{ adults } & \multirow{3}{*}{$\mathrm{Hu}$} & \multirow{3}{*}{1997} & indoor damp & \multirow{3}{*}{ Dr. dx asthma } \\
\hline & & & visible mold & \\
\hline & & & water leaks & \\
\hline & \multirow{5}{*}{ Norbäck } & \multirow{5}{*}{1999} & $>1$ damp & \multirow{5}{*}{$\begin{array}{l}\text { current asthma defined as } \\
\text { combination of bronchial hyper- } \\
\text { responsiveness and at least one } \\
\text { asthma sx in last year }\end{array}$} \\
\hline & & & damp floor & \\
\hline & & & moldy odor & \\
\hline & & & visible mold & \\
\hline & & & water damage or flood & \\
\hline men & Brunekreef & 1992 & damp or mold & Dr. dx. asthma \\
\hline \multirow{2}{*}{$\begin{array}{l}\text { men } \\
\text { women }\end{array}$} & Waegemaekers & 1989 & damp & Dr. dx.asthma or dyspnea \\
\hline & Brunekreef & 1992 & damp or mold & Dr. dx. asthma \\
\hline women & Waegemaekers & 1989 & damp & Dr. $\mathrm{dx}$ asthma or dyspnea \\
\hline \multirow{6}{*}{ children } & \begin{tabular}{|l|} 
Jedrychowski \\
\end{tabular} & 1998 & mold or damp & Dr. dx. asthma \\
\hline & \multirow{3}{*}{ Rönmark } & \multirow{3}{*}{1999} & \multirow{3}{*}{ damp home } & Dr. $\mathrm{dx}$ atopic asthma \\
\hline & & & & Dr. $\mathrm{dx}$ atopic or non-atopic asthma \\
\hline & & & & Dr. dx non-atopic asthma \\
\hline & Slezak & 1998 & damp or mold & Dr. or nurse $\mathrm{dx}$ asthma \\
\hline & Waegemaekers & 1989 & damp & Dr. $\mathrm{dx}$ asthma or dyspnea \\
\hline \multirow{6}{*}{$\begin{array}{l}\text { children \& } \\
\text { adults }\end{array}$} & \multirow{6}{*}{ Williamson } & \multirow{6}{*}{1997} & damp & \multirow{6}{*}{ Dr. dx asthma } \\
\hline & & & damp or condensation current home & \\
\hline & & & damp previous home & \\
\hline & & & mold & \\
\hline & & & severe damp & \\
\hline & & & significant mold & \\
\hline
\end{tabular}

Abbreviations: $\mathrm{sx}=$ symptom; $\mathrm{dx}=$ diagnosis 
Table A1.5 Studies with current asthma as an outcome.

\begin{tabular}{|c|c|c|c|c|}
\hline Subjects & Author & Year & Risk & Outcome description* \\
\hline \multirow{8}{*}{ adults } & \multirow[t]{3}{*}{$\mathrm{Hu}$} & \multirow[t]{3}{*}{1997} & indoor damp & \multirow[t]{3}{*}{$\begin{array}{l}\text { Dr. dx asthma }+s x \text { or medication } \\
\text { in past year }\end{array}$} \\
\hline & & & \begin{tabular}{|l|} 
visible mold \\
\end{tabular} & \\
\hline & & & water leaks & \\
\hline & \multirow{5}{*}{ Norbäck } & \multirow{5}{*}{1999} & $>1$ damp & \multirow{5}{*}{$\begin{array}{l}\text { current asthma defined as } \\
\text { combination of bronchial hyper- } \\
\text { responsiveness and at least one } \\
\text { asthma sx in last year }\end{array}$} \\
\hline & & & damp floor & \\
\hline & & & moldy odor & \\
\hline & & & visible mold & \\
\hline & & & water damage or flood & \\
\hline \multirow{16}{*}{ children } & \multirow{2}{*}{ Brunekreef } & \multirow{2}{*}{1989} & damp ever & \multirow{2}{*}{ Dr. dx asthma in past year } \\
\hline & & & mold & \\
\hline & \multirow{5}{*}{ Dales } & \multirow{5}{*}{1991} & flood & \multirow{5}{*}{ Current asthma confirmed by Dr. } \\
\hline & & & moisture & \\
\hline & & & mold & \\
\hline & & & \begin{tabular}{|l|} 
mold 2 \\
\end{tabular} & \\
\hline & & & mold or damp & \\
\hline & Dekker & 1991 & damp or visible mold & Dr. dx asthma + current sx \\
\hline & \multirow{6}{*}{ Jaakkola } & \multirow{6}{*}{1993} & any damp indicator ever & \multirow{6}{*}{ current Dr. dx asthma } \\
\hline & & & moisture $>1 \mathrm{yr}$ ago & \\
\hline & & & moisture past yr & \\
\hline & & & mold odor past yr & \\
\hline & & & visible mold past yr & \\
\hline & & & water damage $>1$ yr ago & \\
\hline & Taskinen & 1999 & damp home & Dr. dx asthma $+\mathrm{sx}$ \\
\hline & Yang & 1997 & damp home & current Dr. diagnosed asthma \\
\hline \multirow[b]{2}{*}{ students } & \multirow[b]{2}{*}{ Kilpeläinen } & \multirow[b]{2}{*}{2001} & visible mold & \multirow[b]{2}{*}{ current Dr. dx asthma } \\
\hline & & & visible mold, damp stains or water damage & \\
\hline adolescent & Nicolai & 1998 & past or present damp & $>5$ asthma attacks previous yr \\
\hline
\end{tabular}

Abbreviations: $\mathrm{sx}=$ symptom; $\mathrm{dx}=$ diagnosis 
Table A1.6, Studies with asthma development as an outcome.

\begin{tabular}{|c|c|c|c|c|}
\hline Subjects & Author & Year & Risk & Outcome description* \\
\hline \multirow{7}{*}{ adults } & \multirow{3}{*}{ Jaakkola } & \multirow{3}{*}{2002} & damp stains or paint peeling & \multirow{3}{*}{ newly Dr. dx asthma in past year } \\
\hline & & & visible mold or odor & \\
\hline & & & water damage & \\
\hline & \multirow{3}{*}{ Thorn } & \multirow{3}{*}{2001} & damp & \multirow{3}{*}{ Dr. $\mathrm{dx}$ asthma since age $>16$} \\
\hline & & & damp or visible mold & \\
\hline & & & visible mold & \\
\hline & Yang & 1998 & damp or mold or water damage & first-time Dr. dx asthma \\
\hline
\end{tabular}

Abbreviations: $\mathrm{dx}=$ diagnosis 
Appendix 2. Excluded Studies

\begin{tabular}{|c|c|c|c|}
\hline Author & Year & Excluded from & Reason for exclusion* \\
\hline Belanger & 2003 & cough, wheeze & excluded measured conc of microbial agent \\
\hline Dales & 1999 & upper respiratory sx & some sx not upper respiratory sx \\
\hline Dijkstra & 1990 & asthma sx & no clear diagnosis of asthma \\
\hline Engvall & 2002 & upper respiratory sx & excluded throat sx \\
\hline Gent & 2002 & cough, wheeze & $\begin{array}{l}\text { excluded measured conc. of microbial agent; or excluded } \\
\text { humidifier as risk factor }\end{array}$ \\
\hline Infante-Rivard & 1993 & newly diagnosed & excluded humidifier as risk factor \\
\hline Jaakkola & 2002 & newly diagnosed asthma & Excluded studies of risks at workplaces \\
\hline Kilpeläinen & 2001 & common cold $>4 / \mathrm{yr}$ & excluded cold sx \\
\hline Koskinen & 1999 & sore throat & excluded throat sx \\
\hline Mohamed & 1995 & asthma sx & $\begin{array}{l}\text { socio-economic status and housing conditions of the Kenyan } \\
\text { subjects was atypical of that in other studies }\end{array}$ \\
\hline Nafstad & 1998 & bronchial obstr & age $<2$ too early for asthma diagnosis \\
\hline Park & 2001 & wheeze & excluded measured conc. of microbial agent \\
\hline \multirow{2}{*}{ Pirhonen } & \multirow{2}{*}{1996} & asthma sx & ORs are for atopy and should not be used for asthma sx \\
\hline & & dry or sore throat & excluded throat sx \\
\hline Rylander & 1998 & cough, wheeze & excluded risk factors at school \\
\hline \multirow{3}{*}{ Rylander } & \multirow{3}{*}{2000} & \multirow{3}{*}{ cold, sore throat } & excluded cold sx \\
\hline & & & $\begin{array}{l}\text { humidity is not used in our study as an indicator of a dampness } \\
\text { or mold }\end{array}$ \\
\hline & & & excluded throat sx \\
\hline Taskinen & 1999 & asthma sx, cough, wheeze & excluded studies of risks of dampness at school \\
\hline Thorn & 1998 & cough, UR & excluded measured conc. of microbial agent \\
\hline Waegemaekers & 1989 & $\begin{array}{l}\text { wheeze includes shortness of } \\
\text { breath, asthma }\end{array}$ & excluded measured conc. of microbial agent \\
\hline Wever-Hess & 2000 & asthma & age $<2$ too early for asthma diagnosis \\
\hline Wieslander & 1999 & UR & excluded eye sx \\
\hline Yazicioglu & 1998 & asthma sx & excluded self-reported high humidity as risk factor \\
\hline Zock & 2002 & wheeze & meta-analysis itself \\
\hline Øie & 1999 & bronchial obstruction & age $<2$ too early for asthma diagnosis \\
\hline
\end{tabular}

Abbreviations: $\mathrm{sx}=$ symptom 


\section{Appendix 3. Example of original data and results of a meta- analysis.}

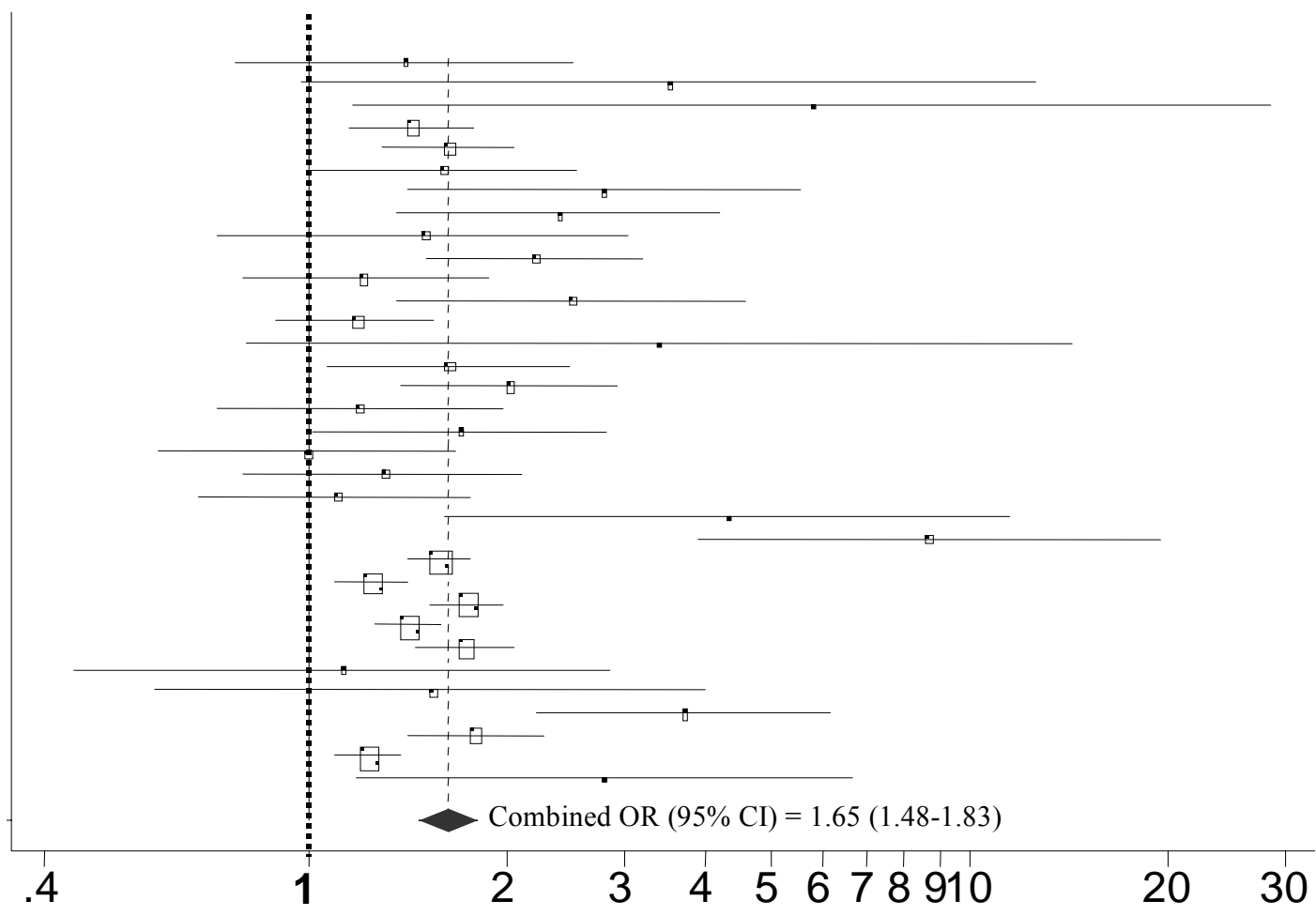

\section{OR for wheeze, random effects model for independent studies}

Figure A3-1. Odds ratios and confidence intervals for wheeze from original studies and from a meta-analysis performed using the random effects model and assuming independent sub-studies. The width of the boxes (some so small they appear as points) is proportional to the precision (inverse of variance) of the study and the ends of the horizontal lines represent lower and upper $95 \%$ confidence limits. The dark vertical line is located at an odds ratio of unity which corresponds to no increased risk of wheeze, while nearly all the reported odds ratios are greater than unity indicating an increase in risk with dampness and mold. The central estimate from the meta-analysis is indicated by the light dashed vertical line and the left- and right-side points of the diamond at the bottom (labeled combined) of the figure indicate the lower and upper 95\% confidence limits from the meta-analysis. 